\title{
Mensuração da Carga de Trabalho de Enfermeiros em Central de Quimioterapia
}

\author{
Measurement of Nursing Workload of Nurses in Chemotherapy Center \\ Medición de la Carga de Trabajo de Enfermeras en el Centro de Quimioterapia
}

\author{
Célia Alves de Souza ${ }^{1}$; Marli de Carvalho Jericó ${ }^{2}$; Márcia Galan Perroca ${ }^{3}$
}

\begin{abstract}
Resumo
Introduçáo: A crescente demanda, o volume de atendimento ambulatorial em oncologia e a complexidade de tratamento têm causado impacto sobre a carga de trabalho dos enfermeiros. Objetivos: Identificar as intervençóes/atividades desenvolvidas por enfermeiros em um Centro Quimioterápico (CQT) segundo a Nursing Interventions Classifications (NIC). Mensurar a carga de trabalho e produtividade desses enfermeiros. Método: Estudo de natureza observacional utilizando técnica de amostragem de trabalho conduzido em CQT na regiáo Sudeste do Brasil, sob o protocolo de Comitê de Ética em Pesquisa aprovado pela instituição de no 290/2010, tendo como participantes sete enfermeiros. O estudo foi realizado em quatro momentos: 1-identificação das intervençôes/atividades; 2-validação de conteúdo; 3- teste-piloto; e 4-mensuraçáo de carga de trabalho. Para identificar as atividades realizadas pelos enfermeiros, foi construído um instrumento utilizando triangulação de dados, combinando três fontes de informaçôes: entrevista semiestruturada, análise de documento e questionário. O instrumento final foi composto por 35 intervençôes e 48 atividades organizadas em cinco domínios (fisiológico básico e fisiológico complexo, comportamental, segurança e sistema de saúde) e 11 classes. Resultados: Obtiveram-se 1.487 amostras de intervençóes/atividades. Observou-se que $43,2 \%$ do tempo dos enfermeiros foram consumidos em cuidados indiretos; $33,2 \%$ em cuidados diretos; $11,6 \%$ em atividades associadas; e $12 \%$ em atividades pessoais. A produtividade média correspondeu a $88 \%$. Conclusão: Os achados desta investigaçáo permitiram concluir que enfermeiros do ambulatório de oncologia consumiram a maior parte de seu tempo em atividades de cuidados indiretos.

Palavras-chave: Serviço de enfermagem; Carga de trabalho; Quimioterapia; Cuidados de enfermagem; Ambulatório hospitalar; Gerenciamento do tempo.
\end{abstract}

\footnotetext{
${ }^{1}$ Docente da Faculdade de Medicina de São José do Rio Preto (FAMERP). São José do Rio Preto (SP), Brasil. Especialista em Enfermagem em Oncologia. Mestre em Ciências da Saúde pela FAMERP. Autor da concepção e planejamento e conclusão do projeto de pesquisa.

${ }^{2}$ Doutor em Enfermagem. Docente da FAMERP (SP), Brasil. Orientadora do projeto.

${ }^{3}$ Doutor em Enfermagem, docente da FAMERP (SP), Brasil. Coorientadora do projeto.

Dissertação apresentada para obtenção do Título de Mestre no Programa de Pós-Graduação FAMERP. Ciências da Saúde. Eixo: Ciências Correlatas. Endereço para correspondência: Célia Alves de Souza. Rua José da Silveira Baldy, no 822 - Jardim São Marco. São José do Rio Preto (SP), Brasil. CEP: 15081-440.E-mail: ca.souza1968@hotmail.com.
} 